\title{
New advances in the use of noninvasive ventilation for acute hypoxaemic respiratory failure
}

\author{
M. Antonelli, M.A. Pennisi, G. Conti
}

New advances in the use of noninvasive ventilation for acute hypoxaemic respiratory failure. M. Antonelli, M.A. Pennisi, G. Conti. (C) ERS Journals Ltd 2003.

ABSTRACT: Noninvasive ventilation (NIV) includes various techniques for augmenting alveolar ventilation without an endotracheal airway. The theoretical advantages of this approach include avoiding the complications associated with endotracheal intubation, improving patient comfort, preserving airway defence mechanisms, speech and swallowing.

The successful application of NIV in hypoxaemic acute respiratory failure (ARF) of varied etiologies has been extensively described but success rate is strictly dependent on ARF etiology and until today the application of NIV strategies in the setting of hypoxaemic ARF is controversial. Larger, controlled studies are required to clarify the role of NIV in the setting of hypoxaemic ARF.

The correct choice of the patient ventilator interface is a crucial issue in noninvasive ventilation. The study of new interfaces could improve tolerability reducing the noninvasive ventilation failure rate.

Eur Respir J 2003; 22: Suppl. 42, 65s-71s.
Istituto di Anestesiologia e Rianimazione, Università Cattolica del Sacro Cuore, Rome, Italy.

Correspondence: M. Antonelli, Istituto di Anestesiologia e Rianimazione, Università Cattolica del Sacro Cuore, Policlinico A. Gemelli, Largo A. Gemelli 8, 00168 Rome, Italy.

Fax: 39063013450

E-mail: m.antonelli@rm.unicatt.it

Keywords: Acute respiratory distress syndrome hypoxaemia noninvasive ventilation respiratory failure
Patients affected by acute hypoxaemic respiratory failure with severe deterioration of gas exchange may require mechanical ventilation (MV) to correct the pathophysiology, reduce the work of breathing, and ameliorate dyspnoea, while concomitant treatments correct the causes of acute respiratory failure (ARF).

Patients commonly receive MV through an endotracheal tube. Conventional invasive MV is a life-saving procedure, however endotracheal intubation (ETI) increases patients discomfort and may cause injuries of the tracheal mucosa [1] and represents one of the most important predisposing factors for developing nosocomial pneumonia [2].

Noninvasive ventilation (NIV) (i.e. the delivery of assisted breaths without an invasive artificial airway) is a safe and effective means of improving gas exchange in patients with ARF. The advantages of this approach could include avoiding the complications associated with ETI, preserving airway defence mechanisms, speech and swallowing with a greater flexibility in instituting and removing MV [2].

The application of noninvasive ventilatory strategies in the setting of acute hypoxaemic respiratory failure is controversial; the international consensus conference on noninvasive mechanical ventilation (NIMV) in ARF stated that "larger, controlled studies are required to determine the potential benefit of adding noninvasive positive pressure ventilation (NPPV) to standard medical treatment of hypoxaemic ARF" [3].

\section{Noninvasive ventilation in hypoxaemic acute respiratory failure}

Hypoxaemic ARF can be the clinical manifestation of several pathologies; the mechanisms responsible for the decrease of arterial oxygen tension $\left(\mathrm{Pa}, \mathrm{O}_{2}\right)$ are diverse (shunt, ventilation/ perfusion mismatch, impairment of alveolar-capillary diffusion).

The efficacy of NIV on patient's outcome predominantly depend on the underlying pathology. Cardiogenic pulmonary oedema (CPE) has been proposed as a cause of hypoxaemic ARF which could respond favourably to NIV application.

In patients with CPE the reduction of lung compliance and the increase of airway resistance induce a marked increase of the work of breathing. The large negative swings in pleural pressure generated by the respiratory muscles increase left ventricular transmural pressure and afterload. Reduction in cardiac output compromises oxygen delivery to the respiratory muscles creating a vicious cycle. Positive pressure ventilation can improve haemodynamic pattern reducing preload and afterload.

Four randomised controlled studies including 206 patients with hypoxaemic ARF due to CPE have been published [4-7]. Patients were treated using continuous positive airway pressure (CPAP) [4-6] or bilevel positive airway pressure (BiPAP) [7]. ETI was required in $15(15 \%)$ of the 102 patients assigned to the NIV group and in $38(37 \%)$ of the 104 patients assigned to conventional treatment. The absolute risk reduction for ETI was $22 \%$ and the number of patients needed to treat with NIV to avoid one tracheal intubation was five. The mortality rate was $13 \%$ in the control group and $8 \%$ in the NIV group.

In a prospective observational study DOMENIGHETTI et al. [8] compared the acute effects of NIV in two groups of patients with hypoxaemic ARF: community-acquired pneumonia (CAP) and CPE. Both groups had a $\mathrm{Pa}, \mathrm{O}_{2} /$ inspiratory oxygen fraction $\left(F I, \mathrm{O}_{2}\right)<200$ at baseline. After $1 \mathrm{~h}$ of NIV both groups had improvement of the $\mathrm{Pa}_{2} \mathrm{O}_{2} / \mathrm{FI}, \mathrm{O}_{2}$, but the subsequent outcome was different depending on the nature of the acute lung injury (ALI). The mean time spent on NIV was $9 \pm 6.3 \mathrm{~h}$ in the CPE and $37 \pm 36 \mathrm{~h}$ in the CAP group ( $\mathrm{p}=0.01)$. 
Intensive care unit (ICU) mortality rate was $6.6 \%$ in the CPE versus $28 \%$ in the CAP group $(\mathrm{p}=0.2)$ [8].

In a multicentre prospective cohort study including 354 patients with hypoxaemic ARF of different origin treated with NIV, ANTONELLI et al. [9] observed the highest failure rate with subsequent intubation in patients with acute respiratory distress syndrome (ARDS) $(51 \%)$ and CAP $(50 \%)$. These two conditions were identified by multivariate analysis as independent risk factors for failure of NIV. In contrast the intubation rate was lower for patients with CPE (10\%) and pulmonary contusion (18\%) [9].

Only a multicentre, randomised controlled trial (RCT) focused on the efficacy of NIV delivered through a face mask in ARF due to CAP [10]. Fifty-six consecutive patients (28 treated with NIV and 28 with conventional medical therapy and oxygen supplementation) were enrolled. The use of NIV was well tolerated, safe, and associated with a significant reduction of respiratory rate, need for ETI $(21 \%$ versus $50 \%$; $\mathrm{p}=0.03)$, and duration of ICU stay ( $1.8 \pm 0.7$ days versus $6 \pm 1.8$ days; $p=0.04)$. The subgroup analysis clearly showed that only hypercapnic patients really benefited from the treatment. An uncontrolled study performed in non-chronic obstructive pulmonary disease patients with CAP confirmed these results, reporting a higher failure rate of NIV (66\%) [11]. Other randomised studies are necessary to clarify the role of NIV in patients with hypoxaemic ARF due to CAP.

Three prospective randomised studies have evaluated the usefulness of NIV in immunocompetent patients suffering from hypoxaemic ARF of various origins [12-14]. WYSOCKI et al. [12] randomised 41 patients with ARF to NIV via face mask versus conventional medical therapy. NIV reduced the need of ETI (36 versus $100 \%, \mathrm{p}=0.02$ ), the duration of ICU stay $(13 \pm 15$ days versus $32 \pm 30$ days, $\mathrm{p}=0.04)$ and mortality rate ( $9 \%$ versus $66 \%, \mathrm{p}=0.06)$ only in patients with associated hypercapnia (carbon dioxide arterial tension $\left(\mathrm{Pa}, \mathrm{CO}_{2}\right)>45 \mathrm{mmHg}$ ), but had no significant advantage in the purely hypoxaemic group.

ANTONELli et al. [13] conducted an RCT comparing NIV via a face mask to ETI with conventional MV, in patients with hypoxaemic ARF who met well-defined criteria for MV, after failure to improve with aggressive medical therapy. Sixty-four consecutive patients ( 32 in each arm) were enrolled. After $1 \mathrm{~h}$ of $\mathrm{MV}$, both groups had a significant $(\mathrm{p}<0.05)$ improvement in $\mathrm{Pa}, \mathrm{O}_{2} / F \mathrm{I}, \mathrm{O}_{2}$. Ten $(31 \%)$ patients randomised to NIV required ETI. Patients randomised to conventional ventilation developed more frequent and serious complications (38\% versus $66 \%, \mathrm{p}=0.02$ ), and infectious complications (pneumonia or sinusitis) related to the endotracheal tube (3\% versus $31 \%$; $\mathrm{p}=0.004)$. Among survivors, patients randomised to NIV had a lower duration of MV $(\mathrm{p}=0.006)$ and a shorter ICU stay $(\mathrm{p}=0.002)$. Factors that may have been involved in shortening the duration of MV in the NIV group included avoiding sedation, eliminating the imposed work by the endotracheal tube, a lower rate of ventilator-associated pneumonia, and an earlier weaning from ventilation.

MARTIN et al. [14] in a RCT compared NIV using BiPAP with usual medical care in the therapy of ARF. Patients were grouped according to the disease cause of ARF and were then randomised to NIV or medical treatment with oxygen supplementation. A total of 32 patients with hypoxaemic ARF were included in the study. Fourteen hypoxaemic patients treated using NIV were compared with 18 patients treated with conventional medical therapy. The NIV group had an ETI rate significantly lower than that of the conventional medical therapy group (7.46 ETI versus 22.64 per 100 ICU days, $\mathrm{p}=0.026$ ).

In conclusion, NIV in immunocompetent patients with acute hypoxaemic respiratory failure was found to be as effective as conventional ventilation in improving gas exchange abnormalities, and when ETI was avoided reduced the risk of nosocomial pneumonia development.

Some studies (table 1) investigated the use of NIV in patients with ARDS $\left(\mathrm{Pa}, \mathrm{O}_{2} / F \mathrm{I}, \mathrm{O}_{2}<200\right.$, bilateral pulmonary infiltrates at chest radiograph, absence of left atrial hypertension or congestive heart failure [15]) including a total of 185 patients, with a success rate of $58 \%$. The elevated rate of NIV failure in this particular set of patients $(42 \%)$ and their mortality rate $(29 \%)$ suggest a prudent approach. At the present the use of NIV in ARDS patients must be limited to haemodynamically stable patients, who can be closely monitored in an environment where ETI is promptly available, with a medical and nursing staff with an extensive experience of NIV.

\section{Noninvasive ventilation in the treatment of hypoxaemic acute respiratory failure in immunocompromised patients}

Many immunocompromised patients develop ALI or ARDS. In this situation, the early application of positive pressure ventilation is aimed at restoring the decreased lung volume, improving oxygenation, and reducing the work of breathing and the respiratory drive. Usually, ETI is the

Table 1. - Studies on noninvasive ventilation applied to acute respiratory distress syndrome (ARDS) patients and outcome

\begin{tabular}{|c|c|c|c|c|c|c|c|c|c|c|c|}
\hline $\begin{array}{l}\text { 1st author } \\
\text { [ref no.] }\end{array}$ & $\begin{array}{l}\text { Year of } \\
\text { study }\end{array}$ & $\begin{array}{l}\text { Type of } \\
\text { study }\end{array}$ & $\begin{array}{l}\text { No. of } \\
\text { patients }\end{array}$ & $\begin{array}{l}\text { No. of } \\
\text { ARDS }\end{array}$ & $\begin{array}{l}\text { Type of } \\
\text { mask }\end{array}$ & $\begin{array}{l}\text { Mode of } \\
\text { ventilation }\end{array}$ & $\begin{array}{c}\text { PEEP } \\
\text { applied } \\
\mathrm{cmH}_{2} \mathrm{O}\end{array}$ & $\begin{array}{c}\text { Duration } \\
\mathrm{h}\end{array}$ & $\begin{array}{c}\text { Success } \\
\text { n }(\%)\end{array}$ & $\begin{array}{c}\text { ICU } \\
\text { mortality } \\
\text { n }(\%)\end{array}$ & $\begin{array}{c}\text { Mask } \\
\text { intolerance }\end{array}$ \\
\hline COVELLI [16] & 1982 & PNCS & 33 & 33 & Facial & CPAP & $5-7$ & 2448 & $27(81)$ & $5(15)$ & 2 \\
\hline MEDURI [17] & 1989 & PNCS & 10 & 2 & Facial & PSV & $7.5 \pm 6$ & 2448 & $1(50)$ & $1(50)$ & NA \\
\hline PENNOCK [18] & 1991 & PNCS & 31 & 7 & Nasal & BiPAP & $2-12$ & $2-144$ & $5(71)$ & $2(29)$ & 2 \\
\hline MEDURI [19] & 1996 & PNCS & 158 & 3 & Facial & PSV & $7-14$ & $32 \pm 6$ & $1(33)$ & $1(33)$ & NA \\
\hline PATRICK [20] & 1996 & PNCS & 11 & 2 & Facial & PSV & $5-8$ & $3-48$ & $0(0)$ & $1(50)$ & 2 \\
\hline RABITSH [21] & 1998 & PNCS & 1 & 1 & Facial & CPAP & 8 & 96 & $1(100)$ & $0(0)$ & 0 \\
\hline ANTONELLI [13] & 1998 & $\mathrm{RCT}$ & 32 & 7 & Facial & PSV & $5-10$ & $24-144$ & $4(58)$ & $2(28)$ & 1 \\
\hline ROCKER [22] & 1999 & PNCS & 10 & 10 & Facial & PSV/CPAP & $5-10$ & $23-166$ & $8(66)$ & $3(30)$ & 1 \\
\hline ANTONELLI [9] & 2001 & PNCS & 354 & 86 & Facial & PSV/CPAP & $5-8$ & $24-96$ & $42(49)$ & $26(30)$ & NA \\
\hline ANTONELLI [23] & 2000 & $\mathrm{RCT}$ & 20 & 8 & Facial & PSV & $8-10$ & $36-120$ & $5(63)$ & $3(37)$ & NA \\
\hline HILBERT [24] & 2001 & $\mathrm{RCT}$ & 52 & 26 & Facial & PSV & $6 \pm 1$ & 144 & $14(54)$ & $10(38)$ & \\
\hline Total & & & 712 & 185 & & & & & $108(58)$ & 54 (29) & \\
\hline
\end{tabular}

Data are presented as range or mean \pm SD unless otherwise indicated. PNCS: prospective not controlled study; RCT: randomised controlled study; CPAP: continuous positive airway pressure; BiPAP: bilevel positive airway pressure; PSV: pressure-support ventilation; PEEP: Positive endexpiratory pressure; ICU: intensive care unit; NA: not applicable. 
conventional way to administer positive pressure ventilation; however the presence of an endotracheal tube represents the main risk factor for the development of nosocomial pneumonia. It is known that in immunocompetent patients, ETI induces a $1 \%$ increase of risk for pneumonia per day of MV [25]. This aspect increased the interest for the application of NIV techniques, which seem able to decrease the rate of nosocomial infectious complications, with a similar level of efficacy in terms of gas exchanges improvement and patients acceptation. In a recent prospective nonrandomised study RocCO et al. [26] evaluated the role of NIV in a group of 21 patients developing ARF after bilateral lung transplantation. All the patients received noninvasive pressure support ventilation (NIPSV) through a face mask. Eighteen patients $(86 \%)$ avoided intubation. No patient treated successfully with NIV died [26].

ANTONELLI et al. [23] conducted a randomised study to compare NIV delivered through a face mask to standard treatment with supplemental oxygen administration as a modality to avoid ETI in 40 solid organ transplant recipients with acute hypoxaemic respiratory failure. Twenty patients were randomised to receive NIV and 20 to receive standard treatment with supplemental oxygen administration. The two groups were similar at study entry. Within the first hour of treatment, $14(70 \%)$ patients in the NIV group, and $5(25 \%)$ in the standard treatment group improved their $\mathrm{Pa}, \mathrm{O}_{2} / F \mathrm{I}, \mathrm{O}_{2}$ ratio. Over time, a sustained improvement in $\mathrm{Pa}, \mathrm{O}_{2} / F \mathrm{I}, \mathrm{O}_{2}$ ratio was noted in $12(60 \%)$ patients in the NIV group, and in $5(25 \%)$ randomised to standard treatment $(\mathrm{p}=0.03)$. The use of NIV was associated with a significant reduction in the rate of ETI $(20 \%$ versus $70 \% ; \mathrm{p}=0.002)$, rate of fatal complications $(20 \%$ versus $50 \%$; $\mathrm{p}=0.05)$, length of stay in the ICU of survivors $(5.5 \pm 3$ days versus $9 \pm 4 ; \mathrm{p}=0.03)$ and ICU mortality rate $(20 \%$ versus $50 \%$; $=0.05$ ).

HILBERT et al. [24] conducted a RCT of early intermittent NIV as compared with standard treatment with supplemental oxygen and no ventilatory support, in 52 immunosuppressed patients with severe hypoxaemic ARF. Periods of NIV delivered through a face mask were alternated every $3 \mathrm{~h}$ with periods of spontaneous breathing with supplemental oxygen. Fewer patients in the NIV group than in the standard-treatment group required ETI (12 versus $20, \mathrm{p}=0.03)$, had serious complications ( 13 versus $21, \mathrm{p}=0.02)$, died in the ICU (10 versus 18 , $\mathrm{p}=0.03$ ), or died in the hospital (13 versus $21, \mathrm{p}=0.02)$. The authors concluded that in selected immunosuppressed patients with pneumonia and ARF, early initiation of NIV is associated with significant reductions in the rates of ETI, serious complications and mortality.

Despite the dramatic improvement in the prognosis of human immunodeficiency virus (HIV)-infected patients due to the new antiretroviral drugs, ARF due to Pneumocystis carinii and other opportunistic agents remains the main cause for ICU admission and death among patients with acquired immune deficiency syndrome (AIDS). These patients are generally treated with face-mask CPAP; two groups have reported the use of NPPV (CPAP+pressure-support ventilation (PSV)) in patients with AIDS and hypoxaemic ARF [27, 28].

In a prospective, case control trial that studied AIDS patients with acute hypoxaemic respiratory failure due to $P$. carinii pneumonia [29], 24 subjects who received NIV by facial mask were compared with 24 thoroughly matched controls treated with conventional invasive ventilation. The use of NIV avoided intubation in $67 \%$ of the patients with improved survival $(100 \%$ versus $38 \%, \mathrm{p}=0.003)$. Patients in the NIV group required fewer invasive devices $(\mathrm{p}<0.001)$ and had a lower incidence of pneumothoraces (8.3 versus $37.5 \%$ : $\mathrm{p}=0.039$ ).

\section{Role of the interface}

A recent study by NAVALESI et al. [30] elucidated the importance of the ventilatory interfaces in NIMV. The authors found that in patients with stable conditions, the choice of an appropriate interface improved the performance of NIV more than the mode of ventilation.

Despite the continuous improvement in the mask design, skin necrosis may occur in $7 \%$ of patients treated with NIV for a period exceeding $72 \mathrm{~h}$; however, after discontinuation of NIV, the healing is rapid, usually 7-10 days [31]. Discomfort, claustrophobia, facial skin erythema, air leaks, acneiform rash, eye irritation, nasal bridge ulceration are the most frequent complications of NIV related to the interface and may require discontinuation of noninvasive MV and ETI.

Full face mask usually offers a better improvement of alveolar ventilation, while the nasal mask is better tolerated. Many factors however limit the use of nasal mask in the setting of hypoxaemic respiratory failure. The leaks through the mouth decrease alveolar ventilation and may decrease the efficacy of assisted ventilation [32]; in addition a high flow of gas passes through the nose increasing nasal resistance and reducing nasal ventilation efficacy.

In the attempt to improve performance of the ventilatory interface CRINER et al. [33] tested a total face mask which resembles a hockey mask. This mask uses a soft cuff that seals around the face contour, avoiding direct pressure on facial structures. These authors found that the total face mask may improve comfort, minimise air leakage and improve ventilation.

Tailoring and alternating different types of interface in accordance to patient's characteristics, tolerance and level of cooperation can solve parts of the problems related to interface. Although an immense variety of ventilators and interfaces for NIV are available patients still feel uncomfortable. MEYer and HiLl [34] in a review on NIMV stated: "Several issues relating to the use of NIMV are unresolved. The optimal interface and ventilator design have not been determined, and these may differ among patients".

Attempting to improve tolerability, a transparent helmet was proposed for use with NIV. Theoretically the helmet has important advantages: 1) good tolerability with a satisfactory interaction of the patients with the environment; 2) a fixation system that should carry a lower risk of cutaneous lesions; and 3) unlike the face mask, it can be applied to any patient regardless of face profile.

The helmet (CaStar Starmed, Italy) is made of transparent latex-free PVC. The device allows the patient to see, read and interact with the environment. A rigid ring maintains the cylindrical shape of the device after pressurisation. The helmet is secured by two armpit braces at two hooks (one anterior and the other posterior) on the ring that joins the helmet with the soft collar (fig. 1). The pressure increase during ventilation makes the soft collar seal comfortably to the neck and the shoulders, avoiding air leakage. The helmet is available in three different sizes. Two connectors placed at the two sides of the helmet guarantee the connection to inspiratory and expiratory ports of the ventilator.

A specific seal connector placed on the plastic ring is used to allow the passage of a nasogastric tube (if needed) avoiding air leakage. The connection has an internal adjustable diaphragm that consents the passage of tubes ranging from 3.5-6.5 mm external diameter. This connection can also be used to allow patients to drink through a straw or to be fed a liquid diet (fig. 1). The helmet's volume is $\sim 10 \mathrm{~L}$ (with patient's head inside) and its compliance is $\sim 65 \mathrm{~mL} \cdot \mathrm{cmH}_{2} \mathrm{O}^{-1}$, when a pressure between $10-30 \mathrm{cmH}_{2} \mathrm{O}$ is applied [35]. A new prototype of the helmet equipped with an inflatable cushion 


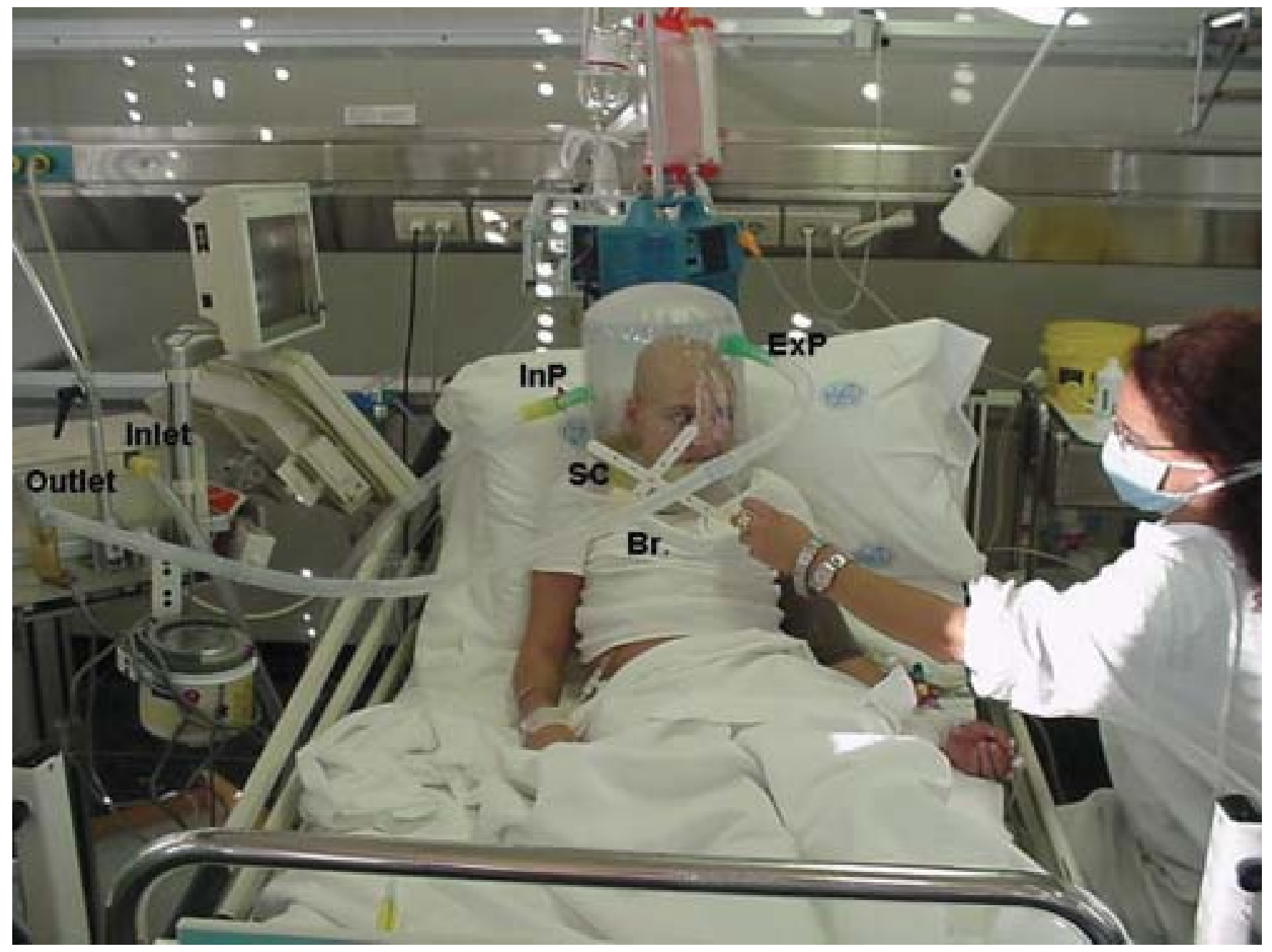

Fig. 1.-Patient ventilated in pressure support with the Helmet. InP: inspiratory port; ExP: expiratory port; Inlet: gas inlet of the mechanical ventilator; Outlet: gas outlet of the mechanical ventilator; SC: sealed connector. The patient is drinking water through the left sealed connection. $\mathrm{Br}$ : armpit braches secured at the anterior hook (the posterior is not visible) of the ring that joins the collar and the transparent part of the helmet.

to reduce the inner volume and with an anti-suffocation valve was recently developed.

During NIV, the latex-free helmet is connected to the ventilator with conventional tubing. Once the helmet is positioned, pressure support is increased in increments of $2-3 \mathrm{~cm}$ of water to obtain patient comfort, a respiratory rate $<25$ breaths $\cdot \mathrm{min}^{-1}$, and the disappearance of accessory muscle activity (as evaluated by palpating the sternocleidomastoid muscle). Positive end-expiratory pressure (PEEP) is increased in increments of $2-3 \mathrm{cmH}_{2} \mathrm{O}$ of water up to $10-12 \mathrm{~cm}$ of water in order to assure a peripheral oxygen saturation of at least $92 \%$ with the lowest $F \mathrm{I}, \mathrm{O}_{2}$ possible. Both flow and pressure triggers can be used. Pressure trigger is usually set at $-1 \mathrm{~cm}$ of water and flow trigger at $5 \mathrm{~L} \cdot \mathrm{s}^{-1}$.

If ETI is required, the helmet can be easily removed within a few seconds and the patient promptly intubated without delay.

The helmet was initially applied with success to deliver CPAP as out-of-hospital treatment for patients with CPE [36]. CPAP was administrated through the helmet connected to a flow oxygen source $\left(>30 \mathrm{~L} \cdot \mathrm{min}^{-1}\right)$ with mechanical PEEP. The system improved oxygen saturation, heart rate, mean arterial pressure, respiratory rate and wet rales score in all patients [36].

Recently the helmet has been proposed as an interface for
NIPSV in patients with acute hypoxaemic respiratory failure, in comparison to NIV delivered via a facial mask [35]. In this prospective pilot clinical trial the primary endpoints were the avoidance of ETI and the incidence of complications in the two groups. Thirty-three consecutive patients affected by hypoxaemic ARF, defined as severe dyspnoea at rest, respiratory rate $>30$ breaths $\cdot \mathrm{min}^{-1}, \mathrm{~Pa}, \mathrm{O}_{2} / \mathrm{FI}, \mathrm{O}_{2}<200$ and active contraction of the accessory muscles of respiration, were enrolled.

These patients were treated with PSV delivered by helmet and were compared with 66 thoroughly matched controls treated with the facial mask. The baseline characteristics and causes of ARF were similar. Both groups improved oxygenation after NIV. Eight patients $(24 \%)$ in the helmet group and 21 patients $(32 \%)$ in the facial mask group failed NIV and were intubated.

No patients failed NIV because of intolerance of the technique in the helmet group, in comparison with eight patients $(38 \%)$ in the mask group. Complications related to the technique (skin necrosis, gastric distension and eye irritation), were fewer in the helmet group, compared with the mask group. The helmet allowed the continuous application of NIV for a longer period of time. The duration of uninterrupted NIV was $36 \pm 29 \mathrm{~h}$ in the helmet group versus $26 \pm 13 \mathrm{~h}$ in the mask group. Length of stay in the ICU, 
intensive care, and hospital mortality were not different. Based on the results of this study, NIV by helmet seems to be as effective as NIV with mask in reducing intubation rate but appear to be more tolerated, permitting prolonged application of NIV, with elevated levels of PEEP without leaks. In this study $24 \%$ of the patients treated with the helmet successfully received NIV in the emergency room before ICU admission. This in accordance with the results proposed by FOTI et al. [36] that suggests the possibility of an effective early treatment with the helmet of hypoxaemic ARF due to CPE. In addition, the helmet allows the patient to communicate, read and drink better than the facial mask, improving acceptance and collaboration between the patient and the medical staff.

In a preliminary report [37] helmet PSV was used to treat 18 patients with early ARDS according to the American College of Chest Physicians/Society of Critical Care Medicine consensus conference [15]. These patients were compared to 36 matched controls with similar characteristics: 18 patients ventilated with facial mask and 18 intubated and assisted with conventional MV. Controls were matched by Simplified Acute Physiology Score, age, and $\mathrm{Pa}, \mathrm{O}_{2} / F \mathrm{I}, \mathrm{O}_{2}$ ratio. The baseline characteristics and causes of ARDS of the three groups were similar. All patients and controls improved their $\mathrm{Pa}, \mathrm{O}_{2} / F \mathrm{I}, \mathrm{O}_{2}$ ratio within the first hour of treatment and over time. Patients in the helmet group had the ability to maintain continuous NIV for a period of time longer than in the mask group (39 \pm 27 versus $24 \pm 12$ ) confirming previous observations [38]. Six $(33 \%)$ of the 18 patients in the helmet group failed noninvasive pressure support ventilation (NIPSV) and required intubation, in comparison to $9(50 \%)$ of the 18 controls treated with the mask. ICU and hospital mortality rate were higher in the ETI group, in comparison with both helmet and mask group but the difference was not statistically significant. Complications and serious events were more frequent in intubated patients $(89 \%)$ than in the helmet $(33 \%)$ and mask $(61 \%)$ group. These data suggest that helmet NPSV could be applied to early ARDS patients to improve gas-exchange and provide a continuous and prolonged application of NIV. Randomised clinical trials are needed before the extensive use of NIV by helmet is recommended in ARDS.

\section{Ventilatory strategies}

A reduction of functional residual capacity (FRC) is the most common cause of $\mathrm{Pa}, \mathrm{O}_{2}$ derangement in acute hypoxaemic respiratory failure and increase of FRC induced by an increase of mean positive airway pressure (mPAP) is effective to correct $\mathrm{Pa}, \mathrm{O}_{2}$ derangement. During pressure-preset ventilation (i.e. PSV), mPAP can be estimated by the following equation:

$$
\mathrm{PSET} \times \mathrm{TI} / \mathrm{T} \text { tot }+\mathrm{PEEP} \times \mathrm{TE} / \mathrm{TT}
$$

where PSET corresponds to the amount of pressure applied, and TI, TE, and TT are inspiratory, expiratory, and total cycle times [39]. Both CPAP and CPAP with PSV improve oxygenation in hypoxaemic patients before (breathing through an endotracheal tube) and after extubation (breathing through a face mask) [40, 41]. Although mask CPAP has been successfully used in reversing hypoxaemia in mild-to-moderate hypoxaemic ARF, PSV associated with PEEP is the most widely used mode of support during NIV and may be more efficient in improving outcome. Recently DelclauX et al. [42] conducted a prospective randomised study on 123 patients with hypoxaemic ARF of different origin. Patients were randomly assigned to receive oxygen therapy alone (61 patients) or oxygen therapy plus CPAP (62 patients). CPAP was associated with improvement of dyspnoea and oxygenation (during the first hour of treatment) as compared with oxygen therapy alone, but did not decrease the rate of ETI ( $34 \%$ versus $39 \%, \mathrm{p}=0.53)$, neither improved outcome. Hospital mortality was similar in the two groups $(31 \%$ versus $30 \%, \mathrm{p}=0.53)$, but a higher number of adverse events occurred with CPAP treatment (18 versus $6, \mathrm{p}=0.01$ ) [42].

Noninvasive ventilatory strategies can cause problems related to patient ventilator interaction. One specific problem during PSV concerns the termination of the breath in presence of air leaks. If the amount of leak flow exceeds the threshold from inspiratory to expiratory phase changeover, the final result is an abnormal prolongation of the inspiration. CALDERINI et al. [43] investigated the short-term effect of two different expiratory cycling mechanisms (time-cycled versus flow-cycled during NIPSV). Each subject received a random sequence of $20 \mathrm{~min}$ conventional flow-cycling (NIPSVfc) and time-cycling inspiratory pressure support ventilation (NIPSVtc). The authors concluded that during NIPSV, in the presence of air leaks, a time-cycled expiratory trigger provides a better patientmachine interaction than a flow-cycled expiratory trigger.

The availability of new ventilators with control of the expiratory trigger sensitivity can partially solve the problem of leak management during NIPSV, by using a pre-set flow threshold above the leak flow rate.

A new ventilatory modality, the proportional assist ventilation (PAV) has recently been investigated in patient receiving NIV. During PAV the ventilator assists the patient providing a specific assist to the resistive and the elastic component of every single breath. The pressure generated by the ventilator is proportional to the patient's effort.

GRASSO et al. [44] evaluated the different response to an increased workload with PSV and PAV in 10 patients during weaning. The capability of keeping tidal volume and minute ventilation constant through increases in inspiratory effort was only preserved during PAV. The ventilatory response to an added respiratory load during PSV required greater muscle effort than during PAV. Using noninvasive PAV in 11 patients with hypoxaemic ARF, PATRICK et al. [45] demonstrated that respiratory rate and the dyspnoea score were significantly reduced after $1 \mathrm{~h}$ of NIV.

\section{Noninvasive ventilation-assisted bronchoscopy}

In subjects affected by pneumonia severe hypoxaemia represents a major contraindication to fibreoptic bronchoscopy (FOB) and/or bronchoalveolar lavage, often inducing the physician to start an empiric treatment. The combination of NIV and FOB can allow an invasive diagnostic approach, avoiding undesired intubations.

In an RCT on 26 nonintubated severely hypoxaemic patients, FOB was performed during facial mask PSV [46]. NIV avoided $\mathrm{Pa}_{\mathrm{a}} \mathrm{CO}_{2}$, heart and respiratory rate deterioration during bronchoscopy. $\mathrm{Pa}, \mathrm{O}_{2} / \mathrm{FI}, \mathrm{O}_{2}$ and $\mathrm{O}_{2}$ saturation significantly increased in the course of NIV and this increment was maintained over the study. The identification of the agent responsible for pneumonia was possible for all patients. None of the patients treated with NIV needed ETI.

The same authors recently proposed the use of noninvasive ventilation delivered by helmet to perform fibreoptic bronchoscopy with bronchoalveolar lavage in adult immunosuppressed patients with suspected pneumonia and severe hypoxia [47]. The specific seal connector placed in the ring of the helmet allowed the passage of the bronchoscope, maintaining assisted ventilation. Helmet noninvasive ventilation avoided gas exchange deterioration during fibreoptic bronchoscopy and bronchoalveolar lavage, with good tolerance. Endotracheal intubation 
was never required during the $24 \mathrm{~h}$ after the procedure. Bronchoscopy with both facial mask and helmet noninvasive ventilation seems to be a feasible, safe and effective technique to allow an early and accurate diagnosis of pneumonia in nonintubated severely hypoxaemic patients.

\section{References}

1. Burns HP, Dayal VS, Scott A, et al. Laryngotracheal trauma: observation on its pathogenesis and its prevention following prolonged orotracheal intubation in the adult. Laryngoscope 1979; 89: 1316-1325.

2. Meduri GU. Noninvasive ventilation in: physiological basis of ventilatory support: a series on lung biology in health and disease. Marini J, Slutsky A, eds. New York, Marcel Dekker, 1998; pp. 921-998.

3. International Consensus Conferences in Intensive Care Medicine: Noninvasive positive pressure ventilation in acute respiratory failure. Intensive Care Med 2000; 27: 166-178.

4. Lin M, Yang Y, Chiany H, Chang M, Chiany BN, Chitlin MD. Reappraisal of continuous positive airway pressure therapy in acute cardiogenic pulmonary edema: short-term results and long-term follow-up. Chest 1995; 107: 1379-1386.

5. Bersten AD, Holt AW, Vedic AE, Skowronski GA, Baggoley CJ. Treatment of severe cardiogenic pulmonary edema with continuous positive airway pressure delivered by face mask. New Engl J Med 1991; 325: 1825-1830.

6. Rasanen J, Heikkila J, Downs J, Nikki P, Vaisanen I, Viitanen A. Continuous positive airway pressure by face mask in acute cardiogenic pulmonary edema. Am J Cardiol 1985; 55: 296-300.

7. Metha S, Jay GD, Woolard RH, et al. Randomized prospective trial of bi-level versus continuous positive airway pressure in acute pulmonary edema. Crit Care Med 1997; 25: 620-628.

8. Domenighetti G, Gayer R, Gentilini R. Noninvasive pressure support ventilation in non COPD patients with acute cardiogenic pulmonary edema and severe community acquired pneumonia: acute effect and outcome. Intensive Care Med 2002; 28: 1226-1232.

9. Antonelli M, Conti G, Moro ML, et al. Predictors of failure of noninvasive positive pressure ventilation in patients with acute hypoxemic respiratory failure: a multi centre study. Intensive Care Med 2001; 27: 1718-1728.

10. Confalonieri M, Della Porta R, Potena A, et al. Acute respiratory failure in patients with severe communityacquired pneumonia: a prospective randomized evaluation of noninvasive ventilation. Am J Respir Crit Care Med 1999; 160: 1585-1591.

11. Jolliet P, Abajo B, Pasquina P, Chevrolet JC. Noninvasive pressure support ventilation in severe community acquired pneumonia. Intensive Care Med 2001; 27: 812-821.

12. Wysocki M, Tric L, Wolff MA, Millet H, Herman B. Noninvasive pressure support ventilation in patients with acute respiratory failure. A randomized comparison with conventional therapy. Chest 1995; 107: 761-768.

13. Antonelli M, Conti G, Rocco M, et al. A comparison of noninvasive positive-pressure ventilation and conventional mechanical ventilation in patients with acute respiratory failure. New Eng J Med 1998; 339: 429-435.

14. Martin TJ, Hovis JD, Costantino JP, et al. A randomized, prospective evaluation of noninvasive ventilation for acute respiratory failure. Am J Respir Crit Care Med 2000; 161: 807-813.

15. Bernard GR, Artigas A, Brigham KL, et al. The AmericanEuropean Consensus Conference on ARDS. Definitions, mechanisms, relevant outcomes, and clinical trial coordination. Am J Respir Crit Care Med 1994; 149: 818-824.

16. Covelli HD, Weled BJ, Beekman JF. Efficacy of continuous positive airway pressure administered by face mask. Chest 1982; 81: 147-150.
17. Meduri GU, Conoscenti CC, Menashe P, Nair S. Noninvasive face mask ventilation in patients with acute respiratory failure. Chest 1989; 95: 865-870.

18. Pennock BE, Kaplan PD, Carlin BW, Sabangan JS, Magovern JA. Pressure support ventilation with a simplified ventilatory support system administered with a nasal mask in patients with respiratory failure. Chest 1991; 100: 1371-1376.

19. Meduri GU, Cook TR, Turner RE, Cohen M, Leeper KV. Noninvasive positive pressure ventilation in status asthmaticus. Chest 1996; 110: 767-774.

20. Patrick W, Webster K, Ludwig L, Roberts D, Wiebe P, Younes M. Noninvasive positive-pressure ventilation in acute respiratory distress without prior chronic respiratory failure. Am J Respir Crit Care Med 1996; 153: 1005-1011.

21. Rabitsch W, Staudinger T, Brugger SA, et al. Successful management of adult respiratory distress syndrome (ARDS) after high-dose chemotherapy and peripheral blood progenitor cell rescue by non-invasive ventilatory support. Bone Marrow Transplant 1998; 21: 1067-1069.

22. Rocker GM, Mackenzie MG, Williams B, Logan PM. Noninvasive positive pressure ventilation: successful outcome in patients with acute lung injury/ARDS. Chest 1999; 115: 173-177.

23. Antonelli M, Conti G, Bufi M, et al. Noninvasive ventilation for treatment of acute respiratory failure in patients undergoing solid organ transplantation. JAMA 2000; 283: 235241.

24. Hilbert G, Gruson D, Vargas F, Valentino R. Noninvasive ventilation in immunosuppressed patients with pulmonary infiltrates, fever and acute respiratory failure. New Eng J Med 2001; 344: 481-487.

25. Fagon JY, Chastre J, Domart Y, et al. Nosocomial pneumonia in patients receiving continuous mechanical ventilation: prospective analysis of 52 episodes with use of a protected specimen brush and quantitative culture techniques. Am Rev Respir Dis 1989; 139: 877-884.

26. Rocco M, Conti G, Antonelli M, et al. Non-invasive pressure support ventilation in patients with acute respiratory failure after bilateral lung transplantation. Intensive Care Med 2001; 27: $1622-1626$.

27. Rabbat A, Lelen G, Bekka F, Leroy F, Schelemmer B, Rochemaure J. NIV in HIV patients with severe pneumocystis carinii pneumonia. Am J Resp Crit Care Med 1995; 151: 427.

28. Meduri GU, Turner RE, Abou-Shala N, Wunderink R, Tolley E. Non invasive positive pressure ventilation via face mask. First line intervention in patients with acute hypercapnic and hypoxemic respiratory failure. Chest 1996; 109: 179-193.

29. Confalonieri M, Calderini E, Terraciano S, et al. Noninvasive ventilation for treating acute respiratory failure in AIDS patients with Pneumocystis carinii pneumonia. Intensive Care Med 2002; 28: 1233-1238.

30. Navalesi P, Fanfulla F, Frigerio P, Gregoretti C, Nava S. Physiologic evaluation of noninvasive mechanical ventilation delivered with three types of masks in patients with chronic hypercapnic respiratory failure. Crit Care Med 2000; 28: $1785-1790$.

31. Antonelli M, Conti G. Noninvasive ventilation in intensive care unit patients. Curr Opin Crit Care 2000; 6: 11-16.

32. Carrey Z, Gottfried SB, Levy RD. Ventilatory muscle support in respiratory failure with nasal positive pressure ventilation. Chest 1990; 97: 150-158.

33. Criner GJ, Travaline JM, Brennam KJ, et al. Efficacy of a new full face mask for noninvasive positive pressure ventilation. Chest 1994; 106: 1109-1115.

34. Meyer TJ, Hill NS. Noninvasive positive pressure ventilation to treat respiratory failure. Ann Intern Med 1994; 120: 760 770 .

35. Scandroglio M, Piccolo U, Mazzone E, et al. Use and nursing of the helmet in delivering non invasive ventilation. Minerva Anestesiol 2002; 68: 475-480. 
36. Foti G, Cazzaniga M, Villa F, et al. Out of hospital treatment of acute pulmonary edema (PE) by non-invasive continuous positive airway pressure (CPAP). Feasibility and efficacy. Intensive Care Med 1999; 25: S112.

37. Antonelli M, Conti G, Pennisi MA, et al. Successful and prolonged application of noninvasive pressure support ventilation by Helmet in patients with ARDS. Abstracts of 15th ESICM Congress Intensive Care Medicine Supplement. Sept 2002; S28: p.78.

38. Antonelli M, Conti G, Pelosi P, et al. New treatment of acute hypoxemic respiratory failure: Non invasive pressure support ventilation delivered by helmet-A pilot controlled trial. Crit Care Med 2002; 30: 602-608.

39. Marini JJ, Ravenscraft SA. Mean airway pressure: physiologic determinants and clinical importance - Part 1: Physiologic determinants and measurements. Critical Care Med 1992; 20: 1461-1472.

40. Gregoretti C, Beltrame F, Lucangelo U, et al. Physiologic evaluation of non-invasive pressure support ventilation in trauma patients with acute respiratory failure. Intensive Care Med 1998; 24: 785-790.

41. Jousela I. Endotracheal tube versus face mask with and without continuous positive airway pressure (CPAP). Acta Anaesthesiol Scand 1993; 37: 381-385.

42. Delclaux C, L'Her E, Alberti C, et al. Treatment of acute hypoxemic nonhypercapnic respiratory insufficiency with continuous positive airway pressure delivered by a face mask: a randomized controlled trial. JAMA 2000; 284: 23522360.

43. Calderini E, Confalonieri M, Puccio PG, Francavilla N, Stella L, Gregoretti C. Patient-ventilator asynchrony during noninvasive ventilation: the role of expiratory trigger. Intensive Care Med 1999; 25: 662-667.

44. Grasso S, Puntillo F, Mascia L, et al. Compensation for increase in respiratory workload during mechanical ventilation: pressure-support versus proportional-assist ventilation. Am J Respir Crit Care Med 2000; 161: 819-826.

45. Patrick W, Webster K, Ludwig L, Roberts D, Wiebe P, Younes M. Noninvasive positive-pressure ventilation in acute respiratory distress without prior chronic respiratory failure. Am J Respir Crit Care Med 1996; 153: 10051011.

46. Antonelli M, Conti G, Rocco M, et al. Noninvasive posititve pressure ventilation vs conventional oxygen supplementation in hypoxemic patients undergoing diagnostic bronchoscopy. Chest 2002; 121: 1149-1154.

47. Antonelli M, Pennisi MA, Conti G, et al. Fiberoptic bronchoscopy during noninvasive positive pressure ventilation delivered by helmet. Intensive Care Med 2003; 29: 126129. 